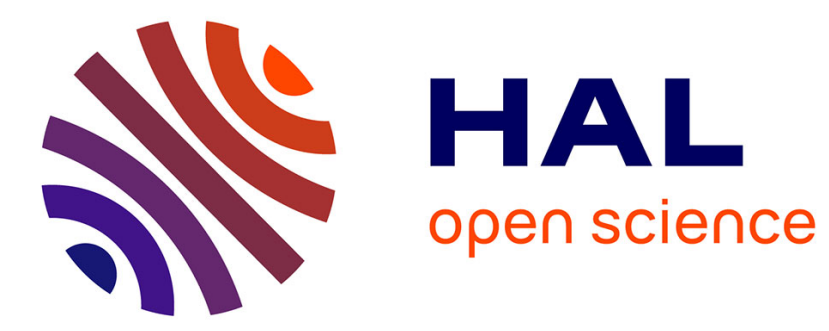

\title{
Dichloroacetate metabolically targeted therapy defeats cytotoxicity of standard anticancer drugs
}

\author{
Dirk Heshe, Stephanie Hoogestraat, Christine Brauckmann, Uwe Karst, \\ Joachim Boos, Claudia Lanvers-Kaminsky
}

\section{To cite this version:}

Dirk Heshe, Stephanie Hoogestraat, Christine Brauckmann, Uwe Karst, Joachim Boos, et al.. Dichloroacetate metabolically targeted therapy defeats cytotoxicity of standard anticancer drugs. Cancer Chemotherapy and Pharmacology, 2010, 67 (3), pp.647-655. 10.1007/s00280-010-1361-6 . hal-00595954

\section{HAL Id: hal-00595954 \\ https://hal.science/hal-00595954}

Submitted on 26 May 2011

HAL is a multi-disciplinary open access archive for the deposit and dissemination of scientific research documents, whether they are published or not. The documents may come from teaching and research institutions in France or abroad, or from public or private research centers.
L'archive ouverte pluridisciplinaire HAL, est destinée au dépôt et à la diffusion de documents scientifiques de niveau recherche, publiés ou non, émanant des établissements d'enseignement et de recherche français ou étrangers, des laboratoires publics ou privés. 


\section{Dichloroacetate Metabolically Targeted Therapy Defeats Cytotoxicity of Standard Anticancer Drugs}

Dirk Heshe $^{1 *}$, Stephanie Hoogestraat ${ }^{1}$, Christine Brauckmann ${ }^{2}$, Uwe Karst ${ }^{2}$, Joachim Boos ${ }^{1}$, Claudia Lanvers-Kaminsky ${ }^{1}$

${ }^{1}$ University Children's Hospital, Department of Paediatric Haematology and Oncology, Albert Schweitzer Str. 33, D-48149 Muenster

${ }^{2}$ Institute of Inorganic and Analytical Chemistry, Corrensstr. 30/36, D-48149 Münster

Correspondence to: $\quad$ Claudia Lanvers-Kaminsky $(P h D)$

University Children's Hospital

Department of Paediatric Haematology and Oncology

Albert-Schweitzer Str. 33

48129 Muenster, Germany

E-mail: lanvers@uni-muenster.de

Phone: 00492518355693 / Fax: 00492518356741

Keywords: DCA, Warburg effect, cancer, cisplatin, cytotoxicity

*This work fulfils the requirements for the medical doctoral thesis of D.H. 


\section{Abstract}

Purpose: The observation that the orphan drug dichloroacetate (DCA) selectively promotes mitochondria-regulated apoptosis and inhibits tumour growth in preclinical models by shifting the glucose metabolism in cancer cells from anaerobic to aerobic glycolysis attracted scientist, clinicians' but also patients' interests and prompted us to further evaluate DCA effects against paediatric malignancies.

Methods: The effects of DCA on mitochondrial membrane potential $(\Delta \Psi \mathrm{m})$, cell viability, and induction of apoptosis were evaluated in paediatric tumour cell lines and the non-malignant cell line HEK293. In addition, combinations of DCA with the standard anticancer drugs cisplatin, doxorubicin, and temozolomide were tested and intra- and extra-cellular platinum species analysed.

Results: DCA selectively induced phosphatidylserine externalisation and reduced $\Delta \Psi \mathrm{m}$ in paediatric tumour cells compared to HEK293 cells, but DCA concentrations $\leq 10 \mathrm{mmol} / \mathrm{L}$ only moderately inhibited the growth of 18 paediatric tumour cell lines. DCA neither influenced the invitro stability of cisplatin nor the cellular cisplatin uptake, but it abrogated the cytotoxicity of cisplatin in 7 out of 10 cell lines. DCA also affected the cytotoxicity of doxorubicin, but did not influence the cytotoxicity of temozolomide. Despite of phosphatidylserine externalisation, DCA failed to activate caspase 3/7 and, moreover, suppressed caspase 3/7 activation by cisplatin and doxorubicin.

Conclusions: Our results indicate that apart from the intriguing effects of DCA on the glucose metabolism of cancer cells the use of DCA for cancer treatment has to be evaluated carefully. Moreover, compassionate use of the orally available drug by cancer patients themselves without medical supervision is strongly discouraged at present. 


\section{Introduction}

Anaerobic glycolysis (also known as Warburg Effect) is a common feature of cancer cells. In contrast to normal cells, which metabolise most of their pyruvate via acetyl-CoA and the Krebs cycle in their mitochondria, malignant cells shift their pyruvate catabolism from this oxygen-dependent pathway to cytoplasmatic, anaerobic glycolysis [1-3]. The generic drug dichloroacetate (DCA) stimulates the activity of the enzyme pyruvate dehydrogenase (PDH) through inhibition of the enzyme pyruvate dehydrogenase kinase (PDK) [4, 5]. Activation of PDH shifts the catabolism of pyruvate from oxygen-independent lactate formation to oxygendependent acetyl-CoA formation. The irreversible conversion of pyruvate into acetyl-CoA results in a sustained activation of the Krebs cycle, which in turn increases the production of reactive oxygen species (ROS) in the mitochondria. The increased concentrations of ROS damage the redox sensitive complex I, inhibit $\mathrm{H}+$ efflux and decrease the mitochondrial membrane potential $(\Delta \Psi \mathrm{m})$. This decrease of $\Delta \Psi \mathrm{m}$ again facilitates the opening of the $\Delta \Psi \mathrm{m}$-sensitive mitochondrial transition pores (MTP) and promotes the efflux of cytochrome c (cyt c) and apoptosis-inducing factor (AIF). In addition, ROS translocated to the cytoplasm reduce the tonic inhibition of caspases by dilating Kv1.5 potassium ion channels and - in a positive feedback loop - by increasing the expression of Kv1.5 potassium channels [6]. DCA was shown to inhibit cell growth over a wide range of tumour cells. In preclinical studies, DCA reduced $\Delta \Psi \mathrm{m}$, induced apoptosis, and inhibited the proliferation of breast cancer, endometrial cancer, prostate cancer, non-small cell lung cancer, and glioblastoma cell lines [6-8]. In preclinical in vivo studies DCA reduced the growth of non-small cell lung cancer xenografts and significantly diminished the number of lung metastasis in a rat mammary adenocarcinoma metastasis model [6,9]. In addition, reversal of the glycolytic phenotype reduced the growth of pancreas tumour xenografts [10]. Since non-malignant cells usually do not use anaerobic glycolysis for energy production, DCA had no effect on proliferation and induction of apoptosis in nonmalignant cells $[6,7]$. Thus, selective modulation of the glycolytic phenotype of cancer cells by DCA seems to be a promising approach for an effective and tolerable treatment of cancer $[11,12]$. For its ability to favour glucose metabolism by aerobic glycolysis, DCA has been used for more than 30 years for 
the treatment of lactate acidosis and inherited mitochondrial diseases in adults as well as in children [13-15]. Though clinical trials in humans with cancer had yet to be performed, DCA was celebrated as the magic bullet against cancer by the public press further stimulating the attraction of DCA for cancer patients. Cancer patients opt for this orally available drug and can purchase it from several distributors [16]. The promising preclinical results against adult malignancies along with the availability of safety data in adults and children provided a strong rationale for the evaluation of DCA against paediatric malignancies. Here we report on the effects of DCA against a panel of 18 immortal tumour cell lines representing six of the most common and aggressive paediatric tumour types. Since DCA by decreasing $\Delta \Psi \mathrm{m}$ is supposed to promote mitochondria mediated apoptosis, we also analysed the combination of DCA with standard anticancer drugs.

\section{Methods}

\section{Reagents}

DCA and temozolomide were purchased from TOCRIS Bioscience (TOCRIS Cookson Ltd., Bristol, UK). Both drugs were dissolved in DMSO (Sigma-Aldrich, Deisenhofen, Germany) and further diluted with complete cell culture medium. Cisplatin was purchased from Gry-Pharma GmbH (Kirchzarten, Germany) and doxorubicin was obtained from Pharmacia GmbH (Karlsruhe, Germany).

\section{Cell culture}

The cytotoxic effect of DCA was tested on a panel of 18 permanent human tumour cell lines including four Ewing sarcoma cell lines (CADO-ES-1, STA-ET1, STA-ET-2.1, VH-64), four neuroblastoma cell lines (IMR5, KCN, SHEP-SF, SH-SY5Y), two medulloblastoma cell lines (MNNG-HOS, UW228.2), two rhabdomyosarcoma cell lines (RD, RH30), two osteosarcoma cell lines (MNNGHOS, OST), two human T-ALL cell lines (CCRF-CEM and MOLT-4), the human B-cell precursor ALL cell line REH and the human acute myeloid leukaemia cell line HL-60. Apart from the human acute myeloid leukaemia cell line HL-60 all 
cell lines were established from tumours of children or adolescents. CCRF-CEM, MOLT-4, REH, HL-60, CADO-ES-1, SH-SY5Y, and RH-30 were purchased from the German Collection of Microorganisms and Cell Cultures (DSMZ, Braunschweig, Germany). DAOY, RD, and IMR-5 were acquired from ATCCLGC (Promochem GmbH, Wesel, Germany). KCN, SHEP-SF, OST, and MNNGHOS were kindly provided by Professor Dr. C. Poremba (Institute of Pathology, University of Duesseldorf, Germany). UW228.2 was allocated by Prof. Dr. Michael Frühwald (University Children's Hospital Muenster, Department of Paediatric Haematology and Oncology, Muenster, Germany) with kindly permission of Prof. John Silber (Department of Neurological Surgery, University of Washington, Washington, Seattle). The Ewing sarcoma cell lines STA-ET-1, STA-ET-2.1, and VH-64 were obtained by courtesy of F. van Valen (University Hospital Muenster, Department of Orthopaedics, Muenster, Germany). All cell lines were grown in RPMI 1640 medium supplemented with $2 \mathrm{mmol} / \mathrm{L} \mathrm{L}$ glutamine, $10 \%$ fetal bovine serum, $10^{5} \mathrm{U} / \mathrm{L}$ penicillin, $100 \mathrm{mg} / \mathrm{L}$ streptomycin, and $25 \mathrm{mg} / \mathrm{L}$ amphotericin B (GibcoBRL cell culture, Invitrogen $\mathrm{GmbH}$, Karlsruhe, Germany). Cells were cultured at $37^{\circ} \mathrm{C}$ in a humidified atmosphere with $5 \% \mathrm{CO}_{2}$. The Ewing sarcoma cell lines were grown on tissue culture flasks coated with collagen.

\section{Cell viability assays}

Screening of cell viability was determined by the well acknowledged MTT assay and the CellTiter-Glo ${ }^{\mathrm{TM}}$ cell viability assay (Promega, Mannheim, Germany). While the MTT assay detects viable cells via reduction of the yellow 3-(4,5dimethylthiazol-2-yl)-2,5-diphenyl-2H-tetrazolium bromide (MTT) (Sigma, Deisenhofen, Germany) to a purple formazan dye by mitochondrial aldehyde dehydrogenases, CellTiterGlo ${ }^{\mathrm{TM}}$ identifies viable cells via their ATP content. The formation of the purple formazan dye correlates with the amount of viable cells and was quantified spectrophotometrically at a wavelength of $560 \mathrm{~nm}$ with an Ascent Multiscan ${ }^{\circledR}$ microplate reader (Thermo Fisher Scientific, Langenselbold, Germany). The ATP released from viable cells after lysis was detected via a luminescent dye, which was quantified with the Fluoroskan Ascent FL (Thermo Fisher Scientific, Langenselbold, Germany). 
Cells were exposed to serial drug dilutions as indicated in the text. The measured absorptions/ luminescence were used to calculate the rate of cell viability compared to untreated controls. In each experiment each concentration was tested in quadruplets and all experiments were repeated at least three times.

\section{Assessment of apoptosis by phosphatidylserine externalisation and $\Delta \Psi \mathrm{m}$}

Cells were seeded at $2 \times 10^{5}$ cells per well into six-well plates and left overnight to adhere and resume exponential cell growth. Then DCA was added and cells were incubated for another $24 \mathrm{~h}$ to $72 \mathrm{~h}$. At the indicated time points, cells were harvested by trypsinization and resuspended in RPMI 1640. Alexa Fluor ${ }^{\mathrm{TM}} 488$ Annexin $\mathrm{V}$ and MitoTracker ${ }^{\mathrm{TM}}$ Red were determined using the Vybrant $^{\mathrm{TM}}$ Apoptosis Assay Kit \#11 (Molecular Probes ${ }^{\mathrm{TM}}$ ). $\Delta \Psi \mathrm{m}$ was analysed by use of the MitoProbe ${ }^{\mathrm{TM}} \operatorname{DiIC}_{1}(5)$ Assay Kit for Flow Cytometry (Molecular Probes ${ }^{\mathrm{TM}}$ ). Fluorescence-activated cells were analysed on a FACScan flow cytometer (Becton Dickinson, San Jose, CA, USA) and data were analyzed using the CellQuest software (Becton Dickinson).

\section{Evaluation of caspase $3 / 7$ activation}

Caspase activation was determined using the caspase-Glo® 3/7 assay supplied by Promega (Mannheim, Germany) according to the manufacturer's instructions. Cells $\left(5 \times 10^{4}\right.$ cells/well) were seeded in white-walled 96 -well plates (Greiner Bio-One GmbH, Solingen, Germany) treated with DCA, cisplatin, and doxorubicin as indicated. Luminescence was measured with the Fluoroskan Ascent FL (Thermo Scientific, Langenselbold, Germany).

\section{Quantification of cellular platinum concentrations}

The total platinum concentration in cells and cell culture medium was determined by inductively coupled plasma-optical emission spectroscopy (ICP-OES) using a Spectro CIROS instrument (Spectro Analytical Instruments, Kleve, Germany). Platinum emission was detected simultaneously at two different emission lines 
(214.40 $\mathrm{nm}$ and $299.97 \mathrm{~nm})$. Cells and cell culture medium were analysed separately. The cells were dissolved in nitric/hydrochloric acid (1/3, v/v) and diluted with bidistilled water. The cell culture medium solutions were diluted with $1 \%$ nitric acid prior to analysis.

\section{Quantification of cisplatin in cell culture medium}

Cisplatin in cell culture medium was determined by application of liquid chromatography coupled to inductively coupled plasma-mass spectrometry (LC/ICP-MS) using an Agilent model 1200 HPLC and an Agilent 7500 ICP-MS (both from Agilent Technologies, Waldbronn, Germany). Cisplatin was identified based on its characteristic retention time in hydrophilic interaction liquid chromatography (HILIC) using a ZIC®-HILIC column (dimensions 150 x 2.1 $\mathrm{mm}$, particle size $3.5 \mu \mathrm{m}$ ) from SeQuant (Marl, Germany) and a mobile phase containing aqueous ammonium formate buffer $(20 \mathrm{mM}$, Sigma Aldrich Chemie $\mathrm{GmbH}$, Steinheim, Germany) with a pH of 7.4 and methanol (Merck, Darmstadt, Germany). An isocratic flow of $60 \%$ methanol was used throughout. Proteins from the cell culture medium were precipitated with acetonitrile (Merck, Darmstadt, Germany) and separated by centrifugation prior to analysis.

\section{Results}

Since DCA was reported to decrease $\Delta \Psi \mathrm{m}$ in adult tumour cell lines already at concentrations of $0.5 \mathrm{mmol} / \mathrm{L}$, we exposed 18 cell lines to seven 10 -fold drug dilutions of DCA ranging from $10 \mathrm{nmol} / \mathrm{L}$ to $10 \mathrm{mmol} / \mathrm{L}$ and only observed a moderate reduction of cell viability at the highest test concentration (Fig. 1). In the medulloblastoma cell lines DAOY and UW228.2, the rhabdomyosarcoma cell lines RD and RH-30, and the Ewing sarcoma cell line CADO-ES-1 DCA concentrations of $10 \mathrm{mmol} / \mathrm{L}$ attenuated cell viability by $30 \%$ to $50 \%$ compared to untreated controls. The DCA effects on cell viability were not related to the rate of cell growth during the time of drug exposure as estimated from the increase of cell viability of untreated controls. Since stimulation of the PDH and the Krebs cycle by PDK inhibition through DCA might at least in part counteract measurements of cell viability, which are based on the activity of mitochondrial aldehyde 
dehydrogenases and cellular ATP content, we also analysed induction of apoptosis by annexin V staining with comparable results. Just like in the cytotoxicity screens, DCA concentrations of $10 \mathrm{mmol} / \mathrm{L}$ only sparsely increased the rate of apoptotic cells. Increasing the dose to $50 \mathrm{mmol} / \mathrm{L}$ DCA raised the rate of apoptotic cells up to $80 \%$ (Fig 2). In accordance with the report of Bonnet et al., this effect was selective for the tumour cell lines, as DCA concentrations of 50 $\mathrm{mmol} / \mathrm{L}$ failed to induce significant levels of phosphatidylserine externalisation in the non-malignant human embryonic kidney 293 cells (Fig 2). In addition, DCA reduced $\Delta \Psi \mathrm{m}$ in a dose dependent manner. However, again exposure to DCA concentrations of $10 \mathrm{mmol} / \mathrm{L}$ for $72 \mathrm{~h}$ only reduced $\Delta \Psi \mathrm{m}$ in a small portion of cells. About $50 \%$ of cells were affected after an exposure to $25 \mathrm{mmol} / \mathrm{L}$ DCA for $72 \mathrm{~h}$ and $\Delta \Psi \mathrm{m}$ of all cells was decreased after exposure to $50 \mathrm{mmol} / \mathrm{L}$ DCA for $72 \mathrm{~h}$ (Fig $3 \mathrm{a}-\mathrm{c}$ ). At DCA concentrations of $50 \mathrm{mmol} / \mathrm{L}$, a reduction of $\Delta \Psi \mathrm{m}$ was measurable already within $5 \mathrm{~min}$ in a small portion of cells. The rate of cells with reduced $\Delta \Psi \mathrm{m}$ increased after $24 \mathrm{~h}$ and after $48 \mathrm{~h} \Delta \Psi \mathrm{m}$ of the whole cell population was reduced (Fig 3d-f). The reduction of $\Delta \Psi \mathrm{m}$ facilitates the release of pro apoptotic factors like cytochrome $\mathrm{c}$ and AIF, which in turn should facilitate apoptosis induced by standard anticancer drugs like cisplatin or doxorubicin. However, when combined with DCA, the cytotoxicity of cisplatin was reduced or even abolished in 7 out of 10 cell lines (Fig 4). The efficacy of cisplatin is based on the formation of an aquo-complex, which is responsible for the platination of DNA and proteins by nucleophiles. In order to exclude alleviation of cisplatin toxicity simply by chemical artefacts due to the high DCA concentrations used, we determined cisplatin concentrations in cell culture medium in the presence and the absence of DCA and found no differences between incubations with and without DCA (Fig 5a). In addition, the cellular uptake of platinum was not affected by DCA (Fig 5b). To determine whether DCA also alleviated the toxicity of other standard anticancer drugs, the cytotoxicity of doxorubicin and temozolomide alone and combined with DCA was analysed on the leukaemia cell lines MOLT-4 and CCRF-CEM. In these cell lines, DCA completely abolished the cytotoxicity of doxorubicin comparable to the DCA effect on cisplatin toxicity (Fig 6a). However, the cytotoxicity of temozolomide was neither reduced nor increased by combination with DCA (Fig 6b). In addition, DCA suppressed caspase 3/7 activation induced by cisplatin (Fig 6c) and doxorubicin (Fig 6d). 
Interestingly, despite induction of phosphatidylserine externalisation as an early event in apoptosis and despite of reduction of $\Delta \Psi \mathrm{m}$, DCA treatment alone failed to activate caspase $3 / 7$.

\section{Discussion}

The outstanding experiments of Bonnet et al. identifying DCA as selective anticancer drug attracted oncologists' and also patients' attention [6-12]. Though clinical trials in humans with cancer had yet to be performed and though accordingly DCA had not been approved for the treatment of cancer by FDA and EMA, it was celebrated as the magic bullet against cancer by the public press further stimulating the attraction of DCA for cancer patients. Cancer patients opt for this orally available drug and can purchase it from several distributors [16]. We evaluated the effects of DCA against paediatric malignancies in vitro and only found moderate effects of DCA. In line with the observations of Bonnet et al., DCA was able to selectively initiate apoptosis in paediatric tumour cell lines compared to non malignant cells. However, high rates of phosphatidylserine externalisation and significant effects on $\Delta \Psi \mathrm{m}$ reduction were only measurable at concentrations of $25 \mathrm{mmol} / \mathrm{L}$, while DCA concentrations of $10 \mathrm{mmol} / \mathrm{L}$ had little or no effect at all. This again was in line with the poor cytotoxic effects of DCA against paediatric tumour cell lines, which we observed at DCA concentrations up to $10 \mathrm{mmol} / \mathrm{L}$. In contrast to some endometrial cancer cell lines no significant increase of cell viability at low DCA concentrations was observed for the cell lines analysed in this study [7]. Some factors might be responsible for the poor effects of DCA observed in this study. First of all anaerobic glycolysis might be less important for the metabolism of the paediatric tumours types studied [17]. However, there are several lines of evidence (i.e. from fluorine-18fluorodeoxyglucose (FDG) positron emission tomography (PET), gene and protein expression profiling) that paediatric like adult tumours have a high glucose turnover and that anaerobic glycolysis might also be relevant for paediatric malignancies [18-22]. Furthermore, the expression of the four PDK isoforms and/or of antiapoptotic proteins, like Bcl-2, PUMA or survivin might have influenced the sensitivity to DCA $[5,7]$. Especially the lack of caspase activation observed by us as well as Sun et al. might be attributed to over 
expression of antiapoptotic proteins [9]. Differences in the expression of Kv1.5 channels might also have discriminated between DCA-sensitive and -resistant cell lines, since activation of Kv1.5 channels by ROS results in a positive feedback loop, which promotes caspase activation [6]. Ongoing studies on the cell line specific glycolytic phenotype along with the cell line specific expression of the different PDK isoforms, Kv1.5 channels, and antiapoptotic proteins will further clarify these issues. Tolerable DCA dosages of $25 \mathrm{mg} / \mathrm{kg} / \mathrm{d}$ given twice daily, which were clinically applied for the treatment of mitochondrial disorders, resulted in peak plasma concentrations of $100-250 \mu \mathrm{mol} / \mathrm{L}$ after the first dose and $200-550 \mu \mathrm{mol} / \mathrm{L}$ after 6 month of therapy [23]. Plasma concentrations of about 1 $\mathrm{mmol} / \mathrm{L}$ were observed after the first application of $50 \mathrm{mg} / \mathrm{kg}$ DCA as well as after chronic exposure to $25 \mathrm{mg} / \mathrm{kg}$ DCA $[15,24]$. Higher plasma concentrations would require higher dosages, whose tolerability has not been evaluated so far. This already argues against an unguarded use of DCA against cancer. Even more important is the fact that DCA was able to fade out the cytotoxicity of standard anticancer drugs. Making cancer cells more susceptible to apoptosis by selectively switching their glucose metabolism from anaerobic to aerobic glycolysis is challenging, since it promises better response of cancer cells to chemotherapy. Bonnet et al. observed a reduction of tumour size by DCA treatment in non-smallcell lung cancer xenografts but no complete remissions [6], which, in addition, argues for the combination of DCA with other anticancer drugs. Dhar and Lippard addressed this issue and designed a new platinum drug, mitaplatin, which consists of one molecule cisplatin with two molecules DCA [25]. Within the cell mitaplatin is reduced and cisplatin and DCA are released. Mitaplatin was toxic against a panel of five mainly adult tumour cell lines, but failed to increase the cytotoxicity of cisplatin. On the contrary against some cell lines (U2OS or HeLa) the cytotoxicity of mitaplatin was decreased compared to cisplatin alone. We tested DCA and cisplatin at a molar ration of 1:100. This excess of DCA might have obliterated the toxicity of cisplatin due to chemical artefacts, however neither intracellular platinum concentrations nor extracellular cisplatin concentrations were influenced by these high DCA concentrations. In addition, the cytotoxicity of doxorubicin, which in contrast to cisplatin exerts its toxicity against tumour cells by inhibition of topoisomerase II and not by DNA modifications, was also attenuated by DCA. The toxicity of temozolomide, 
another DNA modifying agent, however, was not compromised by DCA at the drug concentrations tested. Standard anticancer drugs, like cisplatin, doxorubicin, and temozolomide exert their effects mainly on proliferating cells and concomitant inhibition of proliferation reduces the cytotoxicity of standard anticancer drugs. DCA was reported to inhibit cell proliferation [6-10]. The reduction of cell viability, which we observed in 5 out 18 cell lines, might well be attributed to reduced cell proliferation. However, DCA reduced the cytotoxicity of cisplatin in DCA-sensitive as well as DCA-resistant cell lines suggesting that inhibition of proliferation by DCA was not responsible for the observed reduction of cisplatin toxicity by DCA. Apart from DNA, cisplatin and doxorubicin both impair mitochondrial function. One of the DCA-cisplatin and DCA-doxorubicin interaction sites could be the mitochondrial voltage-dependent anion channel (VDAC). The VDAC plays an important role in the inhibition of apoptosis, but is also part of the mitochondrial transition pore (MTP) as described above, a downstream target of DCA [26]. Interestingly, VDACs seem to be one main target of cellular proteins for cisplatin [27]. Convenient to this hypothesis is the fact that one of the main interaction sites in cells for doxorubicin is the mitochondrial membrane, including VDACs [28]. The finding that there was no effect of DCA to temozolomide induced cell death adds further support to this hypothesis. To date, temozolomide is not known to interact with the mitochondria or the mitochondrial membrane. Further investigations on these interactions could help to decipher drug interactions between DCA and anticancer drugs, which in turn will help to develop optimal strategies for targeting the Warburg effect. The Warburg effect is an interesting selective target for the treatment of cancer, however, our studies underline that targeting the Warburg effect for cancer treatment is far more complex than anticipated and more pre-clinical and clinical work is absolutely necessary to exclude any disadvantage for cancer patients. Moreover, our observations strongly argue against compassionate use of DCA by cancer patients themselves without medical supervision.

\section{Acknowledgements:}

This work was supported by the Karl Bröcker Stiftung Weseke. 
References:

1. Warburg O (1956) On respiratory impairment in cancer cells. Science 124: 269-270

2. Gatenby RA, Gillies RJ (2004) Why do cancers have high aerobic glycolysis? Nat Rev Cancer 4: 891-899

3. Samudio I, Fiegl M, Andreeff M (2009) Mitochondrial uncoupling and the Warburg effect: molecular basis for the reprogramming of cancer cell metabolism. Cancer Res 69: 2163-2166 4. Stacpoole PW (1989) The pharmacology of dichloroacetate. Metabolism 38: 1124-1144 5. Bowker-Kinley MM, Davis WI, Wu P, Harris RA, Popov KM (1998) Evidence for existence of tissue-specific regulation of the mammalian pyruvate dehydrogenase complex. Biochem J 329: $191-6$

6. Bonnet S, Archer SL, Allalunis-Turner J et al (2007) A mitochondria-K+ channel axis is suppressed in cancer and its normalization promotes apoptosis and inhibits cancer growth. Cancer Cell 11: 37-51

7. Wong JY, Huggins GS, Debidda M, Munshi NC, De Vivo I (2008) Dichloroacetate induces apoptosis in endometrial cancer cells. Gynecol Oncol 109: 394-402

8. Cao W, Yacoub S, Shiverick KT, Namiki K, Sakai Y, Porvasnik S, Urbanek C, Rosser CJ (2008) Dichloroacetate (DCA) sensitizes both wild-type and over expressing Bcl-2 prostate cancer cells in vitro to radiation. Prostate 68: 1223-1231

9. Sun RC, Fadia M, Dahlstrom JE, Parish CR, Board PG, Blackburn AC (2009) Reversal of the glycolytic phenotype by dichloroacetate inhibits metastatic breast cancer cell growth in vitro and in vivo. Breast Cancer Res Treat 120: 253-260

10. Chen Y, Cairns R, Papandreou I, Koong A, Denko NC (2009) Oxygen consumption can regulate the growth of tumors, a new perspective on the Warburg effect. PLoS One 4:e7033 11. Xu RH, Pelicano H, Zhou Y, Carew JS, Feng L, Bhalla KN, Keating MJ, Haung P (2005) Inhibition of glycolysis in cancer cells: a novel strategy to overcome drug resistance associated with mitochondrial respiratory defect and hypoxia. Cancer Res 65: 613-621

12. Michelakis ED, Webster L, Mackey JR (2008) Dichloroacetate (DCA) as a potential metabolic-targeting therapy for cancer. Br J Cancer 99: 989-994

13. Stacpoole PW, Nagaraja NV, Hutson AD (2003) Efficacy of dichloroacetate as a lactatelowering drug. J Clin Pharmacol 43: 683-691

14. Stacpoole PW, Gilbert LR, Neiberger RE, Carney PR, Valenstein E, Theriaque DW, Shuster JJ (2008) Evaluation of long-term treatment of children with congenital lactic acidosis with dichloroacetate. Pediatrics 121: 1223-1228

15. Mori M, Yamagata T, Goto T, Saito S, Momoi MY (2004) Dichloroacetate treatment for mitochondrial cytopathy: long-term effects in MELAS. Brain Dev 26: 453-458.

16. Pearson H (2007) Cancer patients opt for unapproved drug. Nature 446: 474-475

17. Chen LB (1988) Mitochondrial membrane potential in living cells. Annu Rev Cell Biol 4:155181

18. Völker T, Denecke T, Steffen I, Misch D, Schönberger S, Plotkin M, Ruf J, Furth C, Stöver B, Hautzel H, Henze G, Amthauer H (2007) Positron emission tomography for staging of pediatric sarcoma patients: results of a prospective multicenter trial. J Clin Oncol 25: 5435-5441. 
19. Chen QR, Song YK, Yu LR, Wei JS, Chung JY, Hewitt SM, Veenstra TD, Khan J (2010)

Global genomic and proteomic analysis identifies biological pathways related to high-risk neuroblastoma. J Proteome Res 9: 373-382.

20. Wellmann S, Guschmann M, Griethe W, Eckert C, von Stackelberg A, Lottaz C, Moderegger

E, Einsiedel HG, Eckardt KU, Henze G, Seeger K (2004) Activation of the HIF pathway in childhood ALL, prognostic implications of VEGF. Leukemia 18:926-933

21. Hulleman E, Kazemier KM, Holleman A, VanderWeele DJ, Rudin CM, Broekhuis MJ, Evans

WE, Pieters R, Den Boer ML (2009) Inhibition of glycolysis modulates prednisolone resistance in acute lymphoblastic leukemia cells. Blood 113: 2014-2021

22. Lu CW, Lin SC, Chen KF, Lai YY, Tsai SJ (2008) Induction of pyruvate dehydrogenase kinase-3 by hypoxia-inducible factor- 1 promotes metabolic switch and drug resistance. J Biol Chem 283:28106-28114

23. Stacpoole PW, Kurtz TL, Han Z, Langaee T (2008) Role of dichloroacetate in the treatment of genetic mitochondrial diseases. Adv Drug Deliv Rev 60: 1478-1487

24. Barshop BA, Naviaux RK, McGowan KA, Levine F, Nyhan WL, Loupis-Geller A, Haas RH (2004) Chronic treatment of mitochondrial disease patients with dichloroacetate. Mol Genet Metab 83: $138-149$

25. Dhar S, Lippard SJ (2009) Mitaplatin, a potent fusion of cisplatin and the orphan drug dichloroacetate. Proc Natl Acad Sci U S A 106: 22199-22204

26. Vyssokikh MY, Brdiczka D (2003) The function of complexes between the outer mitochondrial membrane pore (VDAC) and the adenine nucleotide translocase in regulation of energy metabolism and apoptosis. Acta Biochim Pol 50: 389-404.

27. Yang Z, Schumaker LM, Egorin MJ, Zuhowski EG, Guo Z, Cullen KJ (2006) Cisplatin preferentially binds mitochondrial DNA and voltage-dependent anion channel protein in the mitochondrial membrane of head and neck squamous cell carcinoma: possible role in apoptosis. Clin Cancer Res 12: 5817-5825

28. Tokarska-Schlattner M, Wallimann T, Schlattner U (2006) Alterations in myocardial energy metabolism induced by the anti-cancer drug doxorubicin. C R Biol 329: 657-668 
Legends:

Figure 1: Cell viability of 18 paediatric tumour cell lines from six different tumour types (Ewing sarcoma (EWS), medulloblastoma (MB), Leukaemia, Osteosarcoma (OS), Neuroblastoma (NB), and Rhabdomyosarcoma (RMS) after exposure to $0.1 \mathrm{mmol} / \mathrm{L}$ ( $\square$ ), $1 \mathrm{mmol} / \mathrm{L}$ ( $\square$ ), and $10 \mathrm{mmol} / \mathrm{L}$ ( $\square$ ) DCA for 72h. Cell viability was evaluated by the MTT test.

Figure 2: Annexin V- and Mitotracker ${ }^{\mathrm{TM}}$-staining of CCRF-CEM and HEK293 cells after exposure to DCA concentrations of $10 \mathrm{mmol} / \mathrm{L}$ and $50 \mathrm{mmol} / \mathrm{L}$ for $48 \mathrm{~h}$. Cells were seeded at $2 \mathrm{x}$ $10^{5}$ cells per well into six-well plates and left overnight before DCA was added.

Figure 3: Dose- and time-dependent reduction of $\triangle \Psi \mathrm{m}$. CCRF-CEM cells were exposed to 10 $\mathrm{mmol} / \mathrm{L}$ DCA (a), $25 \mathrm{mmol} / \mathrm{L} \mathrm{DCA} \mathrm{(b),} \mathrm{and} 50 \mathrm{mmol} / \mathrm{L} \mathrm{DCA} \mathrm{(c)} \mathrm{for} 72 \mathrm{~h}$ and to $50 \mathrm{mmol} / \mathrm{L} \mathrm{DCA}$ for $5 \mathrm{~min}(\mathrm{~d}), 24 \mathrm{~h}(\mathrm{e})$, and $48 \mathrm{~h}$ (f). Cells were seeded at $2 \times 10^{5}$ cells per well into six-well plates and left overnight before DCA was added. The grey line represents the $\Delta \Psi \mathrm{m}$ of untreated controls and the black line the $\Delta \Psi \mathrm{m}$ of DCA-treated cells.

Figure 4: Cell viability of paediatric tumour cell lines exposed to DCA, cisplatin, and a combination of both for 72h. Cisplatin and DCA were combined in a constant ratio of 1:100 $(\square 1 \mathrm{mmol} / \mathrm{L}$ DCA, $\square 10 \mu \mathrm{mol} / \mathrm{L}$ Cisplatin, $\square 1 \mathrm{mmol} / \mathrm{L}$ DCA $+10 \mu \mathrm{mol} / \mathrm{L}$ Cisplatin;

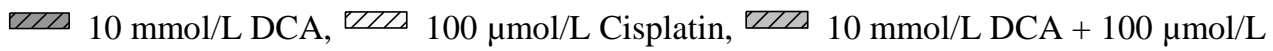
Cisplatin)

Figure 5: To exclude chemical artefacts for the alleviation of cisplatin toxicity cisplatin concentrations were determined in cell culture medium after $4 \mathrm{~h}$ and $24 \mathrm{~h}$ in the presence and absence of DCA. CCRF-CEM cells were incubated with $100 \mu \mathrm{mol} / \mathrm{L}$ cisplatin alone ( ) or in along with $10 \mathrm{mmol} / \mathrm{L} \mathrm{DCA}(\square)$ ).

Figure 6: a. Cell viability of CCRF-CEM and MOLT-4 cells exposed for $72 \mathrm{~h}$ to $1 \mathrm{mmol} / \mathrm{L}$ DCA ( ), $10 \mu \mathrm{mol} / \mathrm{L}$ doxorubicin ( $\square$ ) or a combination of both ( $\square$ ). b. Cell viability of CCRF-CEM and MOLT-4 cells exposed for 72h to $10 \mathrm{mmol} / \mathrm{L}$ DCA ( ), $100 \mu \mathrm{mol} / \mathrm{L}$ temozolomide ( $\square$ ) or a combination of both ( $\square$ ). The solid lines represent the viability of untreated controls. $\mathrm{c}$ and d. Caspase 3 activation in CCRF-CEM cells exposed to increasing DCA concentrations either alone $(\square$ ) or combined $(\square$ ) with $100 \mu \mathrm{mol} / \mathrm{L}$ cisplatin or $10 \mu \mathrm{mol} / \mathrm{L}$ doxorubicin. Caspase 3 activation was analysed after $24 \mathrm{~h}$. Cells $\left(5 \times 10^{4}\right.$ cells/well) were seeded and treated with DCA, cisplatin, and doxorubicin as indicated. Caspase activation was analysed $24 \mathrm{~h}$ after drug exposure. 